Original Research Paper

\title{
The Implementation of Online Learning for Early Detection of Cervical Cancer
}

\author{
${ }^{1,2}$ Hery Harjono Muljo, ${ }^{2}$ Bens Pardamean and ${ }^{1,2}$ Anzaludin Samsinga Perbangsa \\ ${ }^{I}$ Department of Information System, School of Information System, Bina Nusantara University, Jakarta, Indonesia \\ ${ }^{2}$ Bioinformatics and Data Science Research Center, Bina Nusantara University, Jakarta, Indonesia
}

Corresponding Author:

Bens Pardamean

Bioinformatics and Data

Science Research Center, Bina

Nusantara University, Jakarta,

Indonesia

Email: bpardamean@binus.edu

\section{Introduction}

Cancer is a disease in which abnormal cells divide without control and can spread to other parts of the body via bloodstream. There are more than 200 different types of cancer. Cancer growth is a process that occurs over many years. Upon reaching the final stage, the possibility of causing mortality exceeds 90 percent (AACR, 2013). One type of cancer, cervical cancer, is an important health issue for women around the world. It is the second most common cancer in women, affecting more than 1.4 million women worldwide (Ferlay et al., 2001) The annual incidence is more than 460,000 cases (Parkin, 2000) while approximately 231,000 women die from the disease (Sherris and Herdman, 2000).

Therefore, in 2005, the World Health Organization (WHO) issued a resolution to prioritize the development of cancer control programs tailored to the socio-economy of each country. To control this disease, health education is needed to increase the knowledge on cervical cancer prevention (Pondaag et al., 2013), because cervical cancer is also strongly influenced by both parity and level of education (Sakila et al., 2014). The Ministry of Health of the Republic of Indonesia recognized the need for training healthcare workers in order to socialize the program quickly and evenly to all corners of Indonesia.
Continuing education units administered through webbased programs is one way to successfully improve the knowledge of cervical cancer screening for Advanced Practice Nurses (APN) (Choma and Mckeever, 2015). This study set out with the aim of developing the online learning, thereby proposing one solution to support the program the Ministry of Health of the Republic of Indonesia in disseminating pertinent information on cervical cancer prevention.

The current method for the socialization of early detection programs for cervical cancer (as conducted by The Ministry of Health) still relies primarily on direct training, which limits the outreach scope. Three problems are identified as main concerns. Both the expansive, archipelagic aspect of Indonesia's geography and limited availability in human resources place significant blocks on the success and impact of direct counselling programs. Additionally, high operational cost emerging from conducting direct counselling also dampens the success of the current program.

The development of online counselling system for early detection of cervical cancer is the solution proposed to tackle the identified, primary concerns. This program offers the ability to expand the outreach span of the counselling program, regardless of aspects such as geographical location, socio-cultural background and 
time frame (Zimeras and Gortzis, 2011). The online aspect not only improves the ability to transcend limitations posed by time and location. It also streamlines operational needs, allowing for more efficient use of limited human resources. This then leads to reduction of operational cost. The combined improvements then lead to a counselling program that increase the quality of life of its participants as well as educating them on medical knowledge related to cervical cancer (Chorbev et al., 2011).

Indicators used to assess the successfulness of this online counselling are the increase in consultation level and the positive reception of the consulting service by participants. (Dobke et al., 2011). Previous studies have focused more on the conformity of content and design of the Learning Management System (LMS) during the dissemination of information on early detection of cervical cancer. The result of these studies was the conception of system, the needs of health representatives and the needs of the system and development of content (Muljo et al., 2015). The next development steps are analysis and design, system prototype and Analysis, Design, Development, Implementation, Evaluation (ADDIE) framework test as an approach of System Development Life Cycle (SDLC). ADDIE framework is an approach that helps instructional designers, any content's developer, or even teachers to create an efficient, effective teaching design by applying the processes of the ADDIE model on any instructional product (Aldoobie, 2015).

\section{Method}

This study used the ADDIE framework as one approach of the Software Development Life Cycle (SDLC) method. SDLC is a software development method developed systematically to increase the likelihood of completing software projects within the time limit set while simultaneously maintaining the quality of software products according to standards (Mishra and Dubey, 2013). The ADDIE framework is performed in five process stages: Analysis, design, development, implementation and evaluation. ADDIE is a common approach used in the development of learning and training programs. This approach provides clear stages for implementation and effective instruction. ADDIE framework provides processdevelopment projects with the necessary guidelines to solve problems related to the learning process (Peterson, 2003), as depicted in Fig. 1.

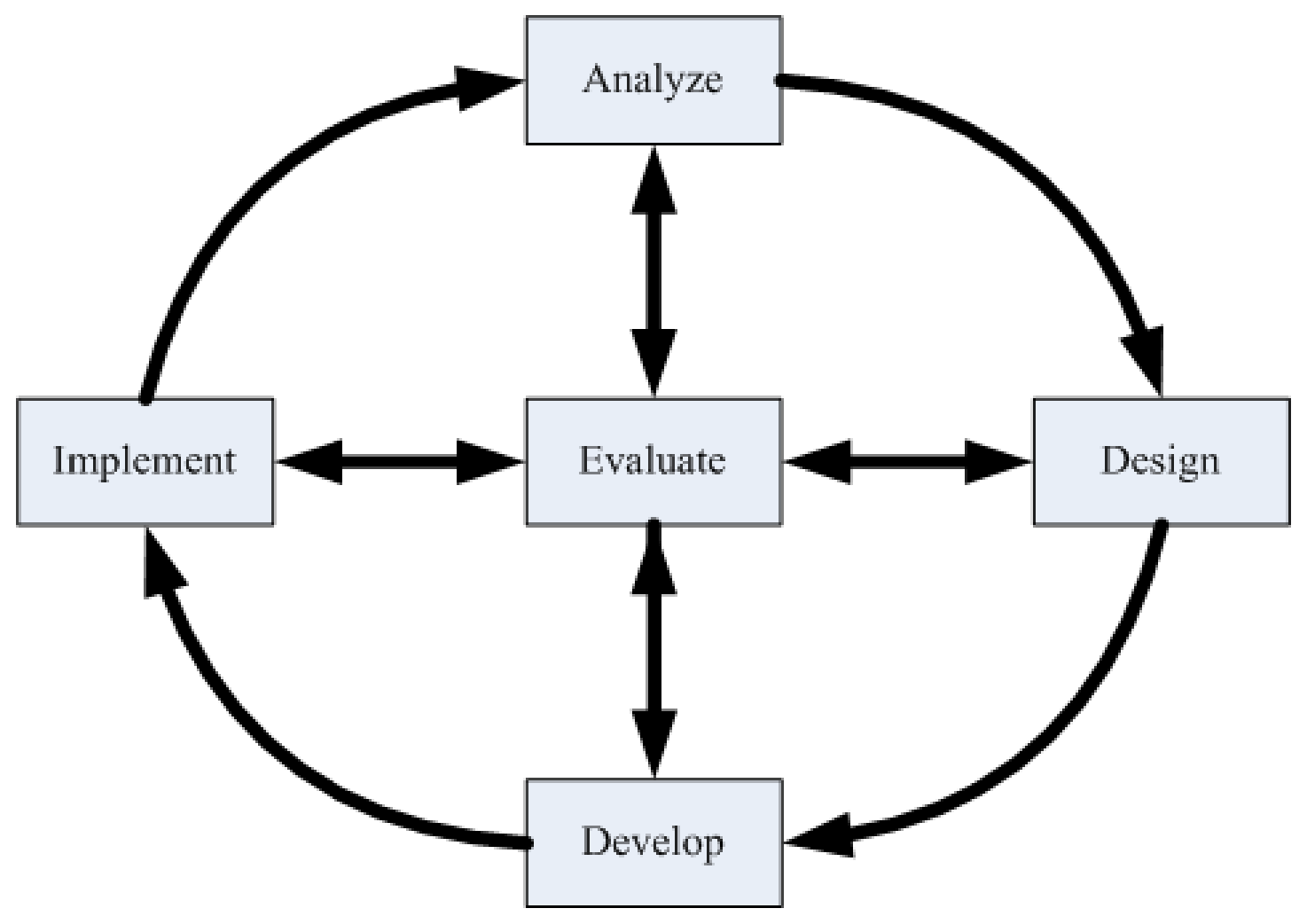

Fig. 1: ADDIE model 


\section{Result and Discussion}

The LMS and content of online learning in the study were built based on a previous study design engineered to fit system requirements of early detection of cervical cancer information dissemination. Supported by currently existing features, such as forums and chat interactions, the LMS enabled simultaneous and real-time learning and teaching sessions that are free from the constraints of geographical distance/location and time (Muljo et al., 2015). The LMS homepage shown in Fig. 2 consists of header (A), breadcrumb (B), course navigation (C), forums/news/events/activity navigation (D), content of page $(E)$ and learning management navigation $(F)$.

In the header, there are settings for menu and user profile as well as language option. Breadcrumb is an indicator position which pages are being visited by the user. Course navigation is useful for users to go directly to the learning content that piqued their interest. While the forums, news, events and activity navigation is provided to allow users to see the latest developments in learning activities. Learning content section contains teaching materials prepared by topic. The learning management navigation is provided for administrators to manage online learning processes, such as the display settings page, the quiz questions/question bank page and other operational activities.
Figure 3 is a user interface that users see upon accessing a discussion forum. The feature of discussion forums was designed to collect questions and feedback from learners to inquire further about various topics and increase the learners' interactions. Features discussion forum is also provided to support online quizzes feature. Learners who take the online quizzes are significantly better in absorbing the material compared to those who only involve in discussion or only taking quizzes. Discussion forum is advisable to enhance the activity of learners in the learning process.

The discussion forum was opened in conjunction with the ongoing learning materials. However, some questions requiring responses from a specialist were answered on the third and fifth day of every week of learning. It was designed with consideration of the tight schedule of the specialists. Through the integration of elearning in medical education, the role of educators shifted from relatively passive, content distributor to active facilitator of learning.

User interface of the quiz section from one of the topics of learning can be seen in Fig. 4. The problems are presented in the multiple-choice form and should be completed within a specified time. Quizzes are given at the end of each topic to evaluate the learner's level of understanding in learning the materials.

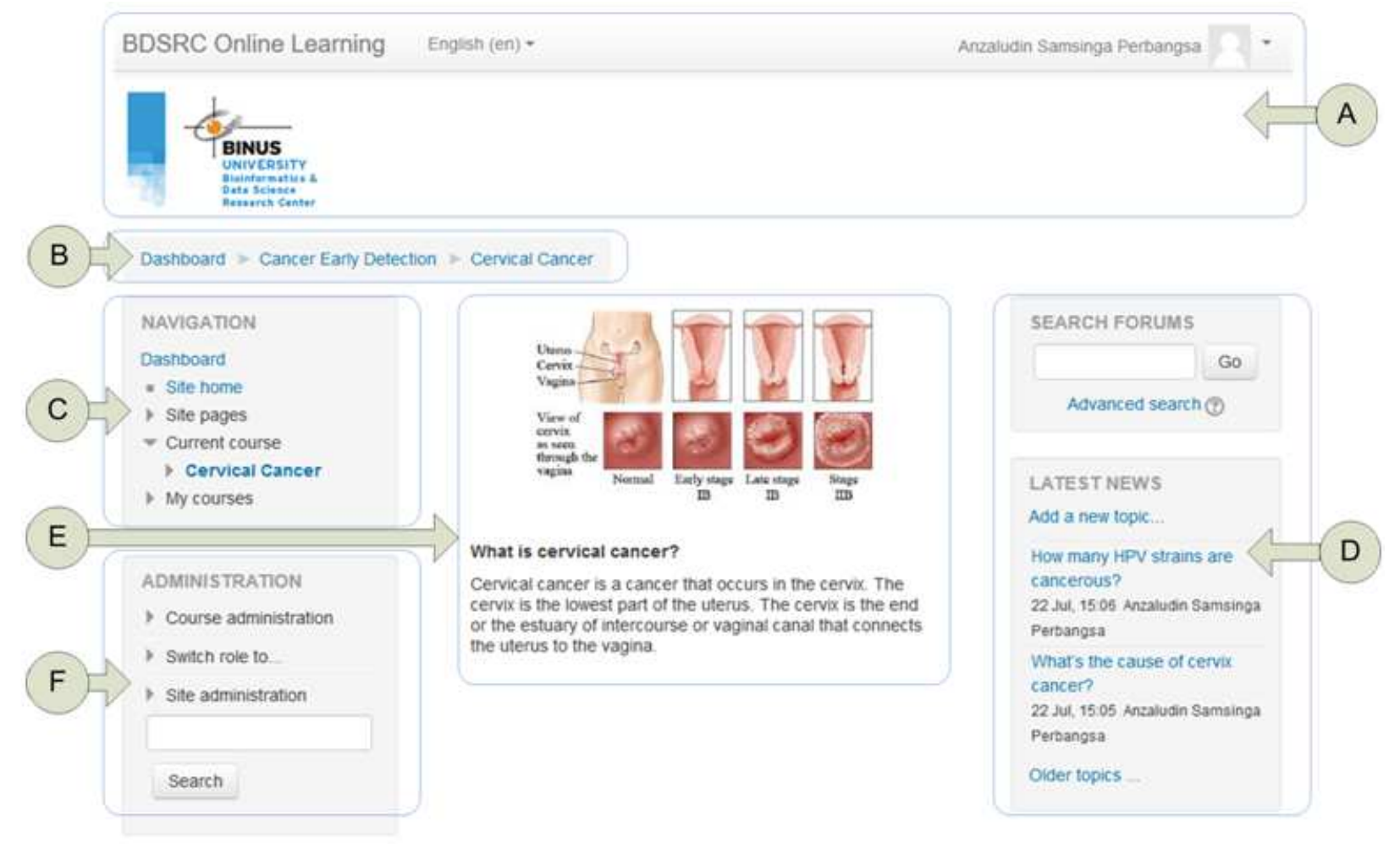

Fig. 2: LMS structure 
Add a new topic

\begin{tabular}{l|ccr}
$\begin{array}{l}\text { Discussion } \\
\text { How many HPV strains are cancerous? }\end{array}$ & Started by & Replies & Last post \\
& Anzaludin Samsinga Perbangsa & 1 & Anzaludin Samsinga Perbangsa \\
Wed, 22 Jul 2015, 3:06 PM
\end{tabular}

How many HPV strains are cancerous?

What's the cause of cervix cancer?

How many HPV strains are cancerous?
by Anzaludin Samsinga Perbangsa - Wednesday, 22 July $2015,3: 06 \mathrm{PM}$
There are certain common strains that are cancer causing, there's a whole other group that causes warts and then there are others that we don't even know what they
do. Every time we review data or recent research, the number of HPV strains keeps expanding. It started off with just a couple of strains, then it went to maybe 10 or 11 ,
then to 40 to 50 and now to more than 100 .
Re: How many HPV strains are cancerous?
by Anzaludin Samsinga Perbangsa - Wednesday, 22 July 2015, 3:06 PM
The cancer-causing strains, most specifically 16 and 18, are the strains that are the most often studied because of their connection to the disease. These two
HPV types cause over 70 percent of cervix cancers.
Show parent | Edit | Split | Delete | Reply

What's the cause of cervix cancer?

Fig. 3: Discussion forum

Question 1
Not yet answered
Marked out of 1.00
P Flag question
* Edit question

Next
Which includes the provision of cervical cancer prevention services at the community level is:

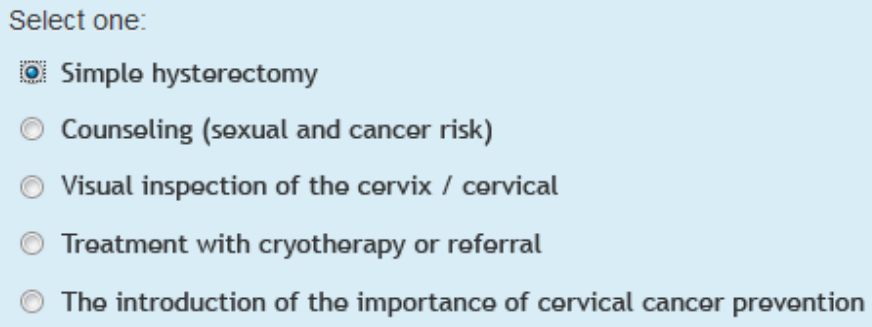

Treatment with cryotherapy or referral

The introduction of the importance of cervical cancer prevention

Fig. 4: An example of an administered quiz

Learners must take the quiz and achieve a certain score in a given chapter before they can gain access to materials of a subsequent next chapter. If learners did not achieve the passing score, they were asked to retake the quiz until satisfactory scores were achieved.

Figure 5 shows the electronic calendar used to record and summarize information on scheduled activities related to the dissemination of knowledge of early detection of cancer, such as workshops and seminars. With the calendar feature, the administrator could create and deploy an invitation event schedule while learners could store and share their schedule with others.

The LMS was developed under a web-based platform with the ability to be used in all operating system platforms using internet browsers like Firefox, Google Chrome, Internet Explorer, Safari and Opera. LMS has 
all the features that were recognized as requirements during the system analysis phase; the features were forums, chat, quizzes, assignments, grading and course section. Each section can display materials in the form of text, image, audio and video. The technologies used in this LMS are listed in Table 1.

The LMS utilized open-source technology to minimize the cost of development and implementation. The platform used is the Linux operating system, Apache web server, MySQL database and server scripts PHP, all of which are optimal choices for developing the LMS. Ubuntu is built on the Linux operating system, which is widely known to have a vast growing ecosystem in terms of quantity, quality and variety of applications as well as in terms of availability of support and other complementary services. Linux combined with Apache, the most popular open-source web server which is tend to be dominant on the web-based applications. However, uncertainty about open-source licenses and potential risk of litigation due to unclear property rights is an obstacle in the use of Linux
(Economides and Katsamakas, 2006). Apache web server is used in this LMS because it provides advantages such as easiness of obtaining support or assistance from the community when encountering technical difficulties, reliable, suitable with the various types of operational state and has a sufficient range of features, all of which can be used freely (Xiao and Dohi, 2010). MySQL can run on more than 20 operating systems, such as Windows (including Windows Server) and Linux-based systems (including Ubuntu and Debian). MySQL's performance, scalability and security system have made it popular to adopt this solution. In addition to the cost aspect, MySQL offers exceptional performance, leading to virtually no compromise in opting for it (Stroe, 2011). PHP is an open-source scripting language for the server-side. It is widely used and provides a rich library functions code, making it ideal for web applications. PHP is also an object-oriented programming language that can take advantage of object-oriented design (Bogunovic et al., 2003).

\section{Calendar}

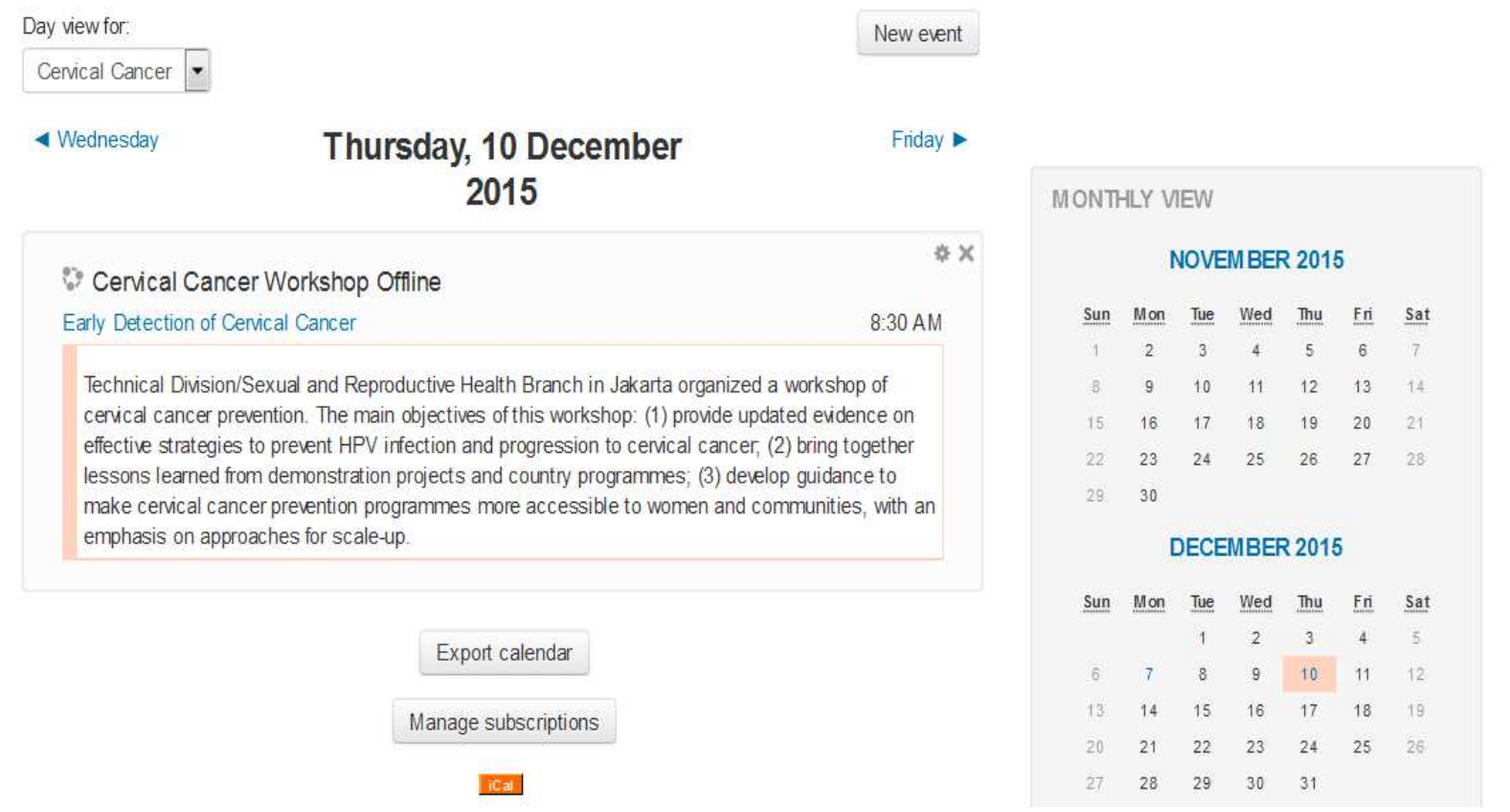

Fig. 5: Electronic calendar

Table 1: System design and technology stack

\begin{tabular}{ll}
\hline Feature & Description \\
\hline Security & Authentication, authorization \\
System design & Web application \\
Web server & Apache 2.4.25 \\
Server script & PHP 7.1.4 \\
Client script & Javascript 1.8.5, HTML 5.0, CSS 3 \\
Database & PostgreSQL 9.6.3 \\
Server operating system & Ubuntu 12.04.1 LTS \\
Client operating system & All \\
\hline
\end{tabular}


The database is designed to receive input data from various types of files, such as comma-separated values (.csv), text (.txt) and Microsoft Excel (.xls or .xlsx). File types that can be used to accommodate the data that have been prepared in accordance with the template for particular purpose. Inputs to the system include data on participants, teachers, classes and the question bank. The system can create output files of results to a database query as comma-separated values (.csv), text (.txt), Microsoft Excel (.xls or .xlsx) and portable document format (.pdf). With this feature, administrators can create status reporting about a participant's progress towards training completion easily and quickly. Similarly, participants who have passed the course post-test, may download and print their certificates electronically as a PDF file. The database consists of 27 tables, which are grouped into 9 master data tables and 18 data transactions tables. The master data table contains data that is rarely changed (persistent), such as class, course, topic, module, forums, threads and question bank. On the other hand, the transaction data table connects two or more tables and is triggered by the occurrence of an action. For example, a student-class table manages the registered student data within a class.

After LMS deployment in the server, each workstation (PC) and notebooks can access the LMS through the Internet, virtually anytime and anywhere. The network topology is shown in Fig. 6.
LMS can improve the efficiency of information dissemination costs because users do not have to pay for transport and accommodation to take the course. The need for high-speed Internet connection can be a limitation to the LMS, particularly in remote areas.

As an effort to develop an online learning, this study builds LMS and content necessary to provide knowledge to the fullest about cervical cancer detection. Inhibiting factors such as financial limitations, motivation, assessment and learning experiences of participants (Assareh and Bidokht, 2011) were overcome through the preparation of a systematic curriculum and the delivery format that involved interactive features. Chat forums, presentations of learning materials and quizzes to measure the participants' understanding of the material are among the interactive features. The printing features of certificates of completion were also provided to increase the motivation of participants to complete the course.

Obstacles from the side of instructors included difficulty to assess learning progress. This was addressed through the inclusion of the question bank and automatic scoring features to streamline the process of administering quizzes. The lack of adequate knowledge about the online learning environment was also another instructor-related obstacle. It was address through the simplification of system use. However, addressing these issues did not lead to significant increase in motivation (Lee et al., 2005).

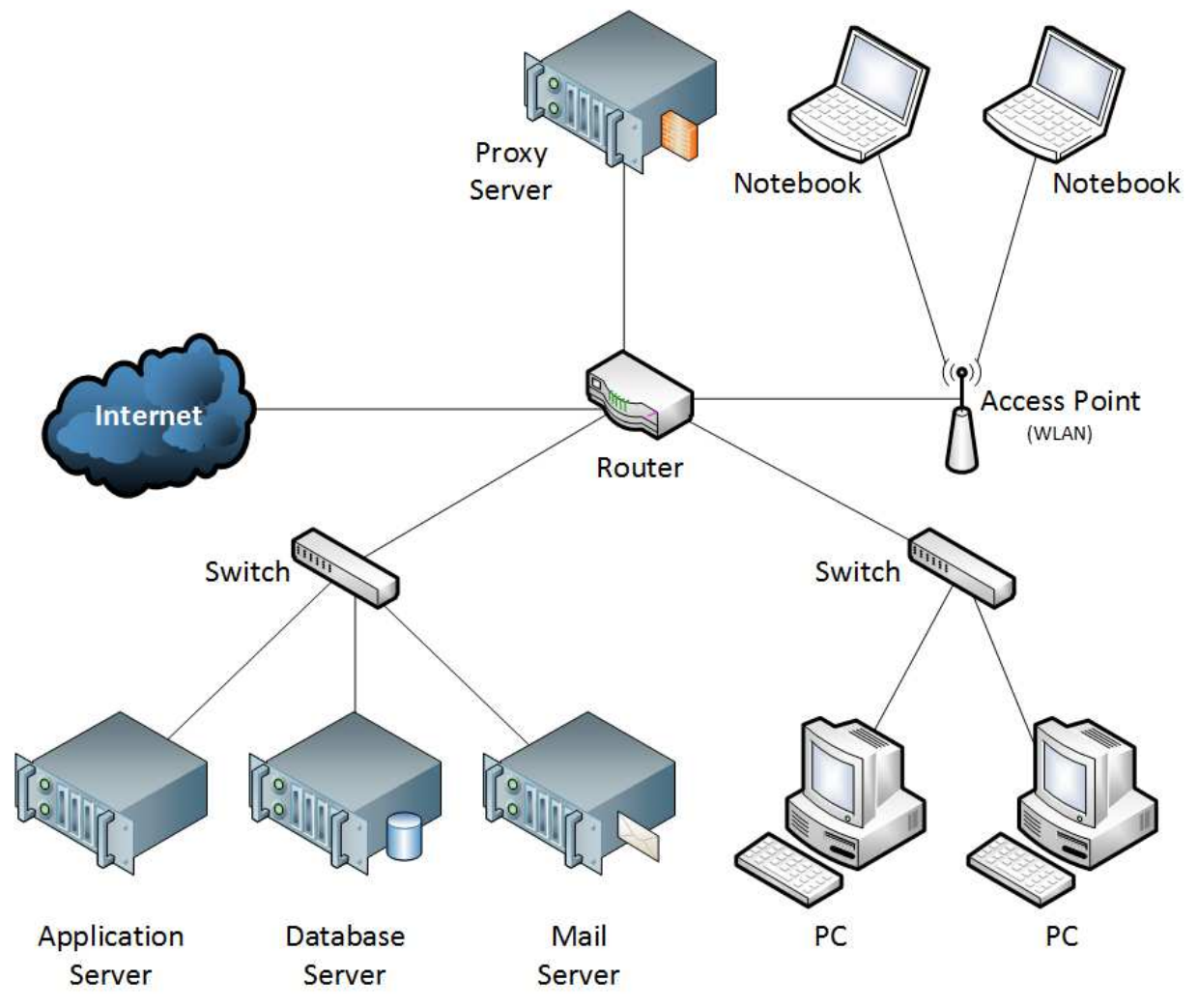

Fig. 6: Network topology 


\section{Conclusion}

This work builds upon a previous study of the contents and the Learning Management Systems (LMS) in order to design an LMS suitable for information dissemination on early detection of cervical cancer that is tailored for Indonesia. The content and LMS are developed to minimize learning obstacles, such as differences in teaching methods and inconsistent materials delivery through the inclusion of forums and chat interactions features. Real-time learning and teaching sessions become possible with less constraints imposed by geographical distance and time. With the support of online learning community services, the learning outcomes of an individual participant could be enhanced.

The online learning and community development is a step forward towards the efforts to reduce the mortality rates and incidence of cervical cancer in Indonesia. Further research is needed to evaluate the user experiences and usability of this LMS in comparison to other online learning media. This study could also become a reference for further research in the topic of LMS development and application for early detection of other types of cancer. The scope of this study is limited to the prototype development using the ADDIE framework approach and will then proceed with data processing of user acceptance in subsequent research.

\section{Acknowledgement}

This study was funded by a Competitive Grant of the Directorate General of Higher Education, Ministry of Education and Culture, Republic of Indonesia.

\section{Author's Contributions}

Hery Harjono Muljo: Organized the study, participated in all experiments and contributes to writing the manuscript.

Bens Pardamean: Designed research method, coordinated data analysis and contributed to writing the manuscript.

Anzaludin Samsinga Perbangsa: Participated in all experiments, performed data analysis and contributed to writing the manuscript.

\section{Ethics}

The author declares that there are no ethical issues that may arise after the publication of this manuscript.

\section{References}

AACR, 2013. AACR cancer progress report 2013. American Association for Cancer Research, Clinical Cancer Research, USA.
Aldoobie, N., 2015. ADDIE Model. Am. Int. J. Contemporary Res., 5: 68-72.

Assareh, A. and M.H. Bidokht, 2011. Barriers to eteaching and e-learning. Procedia Comput. Sci, 3: 791-795. DOI: 10.1016/j.procs.2010.12.129

Bogunovic, H., E. Pek, S. Loncaric and V. Mornar, 2003. An electronic journal management system. Proceedings of the 25th International Conference on Information Technology Interfaces, Jun. 19-19, IEEE Xplore Press, Cavtat, Croatia, pp: 231-236. DOI: 10.1109/ITI.2003.1225350

Choma, K. and A.E. Mckeever, 2015. Cervical cancer screening in adolescents: An evidence-based internet education program for practice improvement among advanced practice nurses. Worldviews Evidence-Based Nursing, 12: 51-60.

Chorbev, I., M. Sotirovska and D. Mihajlov, 2011. Virtual communities for diabetes chronic disease healthcare. Int. J. Telemed. Applic., 2011: 28-35.

Dobke, M.K., D. Bhavsar and F. Herrera, 2011. Do telemedicine wound care specialist consults meet the needs of the referring physician? A survey of primary care providers. Int. J. Telemed. Applic., 2011: 54-60.

Economides, N. and E. Katsamakas, 2006. Linux vs. windows: A comparison of application and platform innovation incentives for open source and proprietary software platforms. Eco. Open Source Software Develop.

Ferlay, J., F. Bray, P. Pisani and D.M. Parkin, 2001. GLOBOCAN 2000: Cancer Incidence, Mortality and Prevalence Worldwide. 1st Edn., IARCPress, Lyon.

Lee, M.K., C.M. Cheung and Z. Chen, 2005. Acceptance of internet-based learning medium: The role of extrinsic and intrinsic motivation. Inform. Manage., 42: 1095-1104.

Mishra, A. and D. Dubey, 2013. A comparative study of different software development life cycle models in different scenarios. Int. J. Adv. Res. Comput. Sci. Manage. Studies, 1: 64-69.

Muljo, H.H., A.S. Perbangsa and B. Pardamean, 2015. Online learning content and learning management system for early detection of cervical cancer. Int. J. Digital Content Technol. Applic., 9: 54-63.

Parkin, M., 2000. Personal communication. Cited in: Preventing cervical cancer in low-resource settings. Outlook, 18: 1-8.

Peterson, C., 2003. Bringing ADDIE to life: Instructional design at its best. J. Educ. Multimedia Hypermedia, 12: 227-241.

Pondaag, C.C., H. Wungouw and F. Onibala, 2013. Pengaruh pendidikan kesehatan terhadap tingkat pengetahuan siswi tentang pencegahan kanker serviks di SMA negeri 1 manado. E J. Keperawatan (e-Kp), 1: 1-6. 
Sakila, A., H. Wijayanegara and M. Kusmiati, 2014. Hubungan antara karakteristik pasien dengan kejadian $\mathrm{Ca}$ servix di rumah sakit al islam kota bandung. Proceedings of Pendidikan Dokter, (PPD'14), pp: 343-349.

Sherris, J. and C. Herdman, 2000. Preventing cervical cancer in low- resource settings. Outlook, 18: 1-8.

Stroe, I.S., 2011. MySQL databases as part of the online business, using a platform based on linux. Database Syst. J., 2: 3-12.
Xiao, X. and T. Dohi, 2010. Estimating the error rate in an apache web server system. Int. J. Software Eng. Applic., 4: 19-28.

Zimeras, S. and L.G. Gortzis, 2011. Interactive teleradiological segmentation systems for treatment and diagnosis. Int. J. Telemed. Applic., 2011: 168-182. 